Funding: Academy of Finland, the Päivikki and Sakari Sohlberg Foundation, the Yrjö Jahnsson Foundation, the Juho Vainio Foundation, the Signe and Ane Gyllenberg Foundation, Tampere University Hospital Medical Research Fund, and Oulu University Hospital Medical Research Fund.

Conflict of interest: None.

1 Kivelä S-L, Pahkala K, Laippala P. Prevalence of depression in an elderly Finnish population. Acta Psychiatr Scand 1988;78:401-13.

2 Pahkala K, Kesti E, Köngäs-Saviaro P, Laippala P, Kivelä S-L. Prevalence of depression in an aged population in Finland. Soc Psychiatry Psychiatr Epidemiol 1995;30:99-106.

3 Pulska T, Pahkala K, Laippala P, Kivelä S-LK. Six-year survival of depressed elderly Finns: a community study. Int J Geriatr Psychiatry 1997;12:942-50.

4 Rosengren A, Orth-Gomer K, Wedel H, Wilhelmsen L. Stressful life events, social support, and mortality in men born in 1933. BMJ 1993;307:1102-5.

5 Thomas C, Kelman HR, Kennedy GJ, Ahn C, Yang C-Y. Depressive symptoms and mortality in elderly persons. J Gerontol Soc Sci 1992;2: S80-87.

(Accepted 16 July 1998)

\title{
Historical cohort study of in utero exposure to uterotonic drugs and cognitive function in young adult life
}

\author{
Henrik Toft Sørensen, Kenneth J Rothman, Matthew W Gillman, Flemming Hald Steffensen, \\ Peer Fischer, Svend Sabroe
}

Oxytocin has potent uterotonic properties which can induce tetany, rupture, and water intoxication. Inappropriately high doses can affect the fetus by inducing abnormal heart rhythms, circulatory collapse, and preterm delivery accompanied by an increased risk of respiratory distress and damage to the central nervous system. ${ }^{1}$ Several studies have reported an association between oxytocic drugs and neonatal hyperbilirubinaemia, ${ }^{2}$ which might influence long term cognitive function. ${ }^{3}$ Little is known, however, of the long term consequences of exposure to uterotonic drugs. We investigated whether in utero exposure to uterotonic drugs affects cognitive performance in draft age men.

\section{Subjects, methods, and results}

Nearly all Danish men have to register with the draft board at around the age of 18 years, at which time they undergo physical and mental examinations. We studied all men who were born in Denmark after 1 January 1973 and who were drafted while residing in North Jutland and Viborg counties from 1 August 1993 to 31 July 1994.

All draftees took a 45 minute intelligence test, the Boerge Prien test, developed in 1957 for the Danish draft board. ${ }^{4}$ The test includes four time limited subtests covering four categories: letter matrices, verbal analogies, number series, and geometric figures. The test shows high correlations with the Weschler adult intelligence scale verbal intelligence quotient (0.78), the performance intelligence quotient (0.71), and the full scale intelligence quotient (0.82). In the validation study the mean full scale intelligence quotient was 106 , equivalent to a mean Boerge Prien test score of 44.2.

We linked data from the draft examination with the Danish Medical Birth Registry by means of a 10 digit unique personal identification number. The registry contains information relating to all births in Denmark since 1973. Oxytocin was the most commonly used uterotonic drug in that period. We examined the mean Boerge Prien test score according to in utero exposure to uterotonic drugs, taking account of possible confounding variables (table).

We identified 4805 conscripts during the study period. We had complete draft medical data on 4300; of the remainder, 495 were exempt from the examination mainly because of asthma, osteochondrosis, and epilepsy, and 10 had incomplete data in the birth registry. Of the 4300 men, $22.8 \%$ had been exposed to uterotonic drugs; among those who were exempt from the examination $23.5 \%$ had been exposed to uterotonic drugs.

The mean Boerge Prien score was similar for those exposed and not exposed to uterotonic drugs (43.1 v 42.9). We also stratified the subjects by mode of delivery; in subjects born by vaginal delivery the mean Boerge Prien score was 43.0 among those exposed to

Descriptive data on 4300 Danish draftees* according to exposure to uterotonic drugs during their delivery. Figures are numbers (percentages) of subjects unless stated otherwise

\begin{tabular}{|c|c|c|}
\hline Detail & $\begin{array}{l}\text { Not exposed } \\
(\mathrm{n}=3289)\end{array}$ & $\begin{array}{l}\text { Exposed } \\
(\mathrm{n}=1011)\end{array}$ \\
\hline \multicolumn{3}{|l|}{ Draftees } \\
\hline \multicolumn{3}{|l|}{ Boerge Prien test score: } \\
\hline Median (range) & $44(5-69)$ & $44(9-68)$ \\
\hline Mean $(95 \% \mathrm{Cl})$ & 43.1 (42.8 to 43.4$)$ & 42.9 (42.3 to 43.5$)$ \\
\hline Quartiles (1-3) & $37-50$ & $37-49$ \\
\hline Median (range) birth weight $(\mathrm{g})$ & $3380(1130-5380)$ & $3630(1630-5380)$ \\
\hline Quartiles of birth weight (1-3) & $3130-3800$ & $3130-3880$ \\
\hline Median (range) birth length $(\mathrm{cm})$ & $52(39-62)$ & $53(40-61)$ \\
\hline Quartiles of birth length (1-3) & $51-54$ & $51-54$ \\
\hline \multicolumn{3}{|l|}{ Gestational age (weeks): } \\
\hline$\geqslant 37$ & $2974(90.5)$ & $926(91.6)$ \\
\hline $34-36$ & $222(6.8)$ & $62(6.1)$ \\
\hline$\leqslant 33$ & $92(2.8)$ & $23(2.3)$ \\
\hline No of caesarean sections & $188(5.7)$ & $76(7.5)$ \\
\hline \multicolumn{3}{|l|}{ Mother } \\
\hline $\begin{array}{l}\text { Median (range) age (years) at } \\
\text { delivery }\end{array}$ & $26(15-43)$ & $26(16-43)$ \\
\hline Quartiles of age (1-3) at delivery & $23-29$ & $23-29$ \\
\hline \multicolumn{3}{|l|}{ Parity: } \\
\hline $0-1$ & $2261(68.7)$ & $724(71.6)$ \\
\hline 2 & $638(19.4)$ & $172(17.0)$ \\
\hline$\geqslant 3$ & $390(11.9)$ & $115(11.4)$ \\
\hline \multicolumn{3}{|l|}{ Employment: } \\
\hline Unemployed, housewife, retired & $869(26.6)$ & $222(22.1)$ \\
\hline Employed & $2219(67.9)$ & $737(73.5)$ \\
\hline Self employed, assisting spouse & $179(5.5)$ & $44(4.4)$ \\
\hline
\end{tabular}

${ }^{*}$ Total number of subjects for each variable is not always 4300 because of missing data.
Department of Internal Medicine V, Aarhus University Hospital, 8000

Aarhus C, Denmark

Henrik Toft

Sørensen,

associate professor

Danish

Epidemiology

Science Centre,

Department of

Epidemiology and

Social Medicine,

University of

Aarhus, 8000

Aarhus C

Flemming Hald

Steffensen,

research associate

professor

Svend Sabroe, associate professor

Department of Epidemiology and Preventive

Medicine, Boston

University School of

Medicine, Boston,

MA 02118, USA

Kenneth J

Rothman,

professor

Department of Ambulatory Care and Prevention,

Harvard Medical

School and

Harvard Pilgrim

Health Care,

Boston, MA 02215

Matthew W

Gillman,

associate professor

Conscription

Administration,

County of North

Jutland, 9000

Aalborg, Denmark

Peer Fischer,

consultant

Correspondence to:

Dr Sørensen

hts@soci.au.dk

BMJ 1999;318:433-4 
uterotonic drugs compared with 43.1 among those not exposed. From a multiple linear regression with all above mentioned confounders included we estimated the difference in Boerge Prien score to be -0.58 (95\% confidence interval -1.25 to 0.08 ) between those exposed and not exposed to uterotonic drugs.

\section{Comment}

Friedman et al examined 156 children 23 to 62 months after births associated with spontaneous labour, labour induced with oxytocin, or labour induced with dinoprostone. The prevalence of neurological or developmental abnormalities not attributable to events after delivery was the same overall in induced and spontaneous labours, but those abnormalities occurring after induction of labour all followed use of oxytocin. ${ }^{5}$ Our data indicate that exposure to uterotonic drugs does not substantially affect cognitive function 20 years later. A small difference due to non-differential misclassification, however, cannot be ruled out. A strength of our study is the large size, the population based design, and complete ascertainment. It is unlikely that selection bias and confounding explain the lack of association.
Contributors: HTS, KJR, and MWG in collaboration with SS initiated the establishment and design of the cohort. HTS initiated this study and discussed the hypothesis with KJR. HTS and FHS analysed the data. PF collected the outcome data. SS linked the data to the birth registry. All authors participated in the interpretation of the findings. HTS, KJR and FHS wrote the first draft of the paper. All participated in editing the paper. HTS is guarantor of the paper.

Funding: Helsefonden (grant No 11/064-94), the EU Biomed II programme (contract No BMH4-CT97-2430), Aarhus University Research Foundation (F-1996-SUN-1-77), and Danish Medical Research Council (grant No 9700677). The activities of the Danish Epidemiology Science Centre are financed by a grant from the Danish National Research Foundation.

Conflict of interest: None declared.

1 Dawood MY. Evolving concepts of oxytocin for induction of labor. Am J Perinatal 1989;6:167-72.

2 Johnson JD, Aldrich M, Angelus P, Stevenson DK, Smith DW, Herschel MJ, et al. Oxytocin and neonatal hyperbilirubinemia. Am J Dis Child 1984; 138:1047-50.

3 Seidman DS, Paz I, Stevenson DK. Neonatal hyperbilirubinemia and physical and cognitive performance at 17 years at age. Pediatrics 1991;88:828-33.

4 Mortensen EL, Reinisch JM, Teasdale TW. Intelligence measured by WAIS and a military draft board group test. Scand J Psychol 1989;30: 3115-8.

5 Friedman EA, Sachtleben MR, Wallace AK. Infant outcome following labor induction. Am J Obstet Gynecol 1979;133:718-22 (Accepted 14 August 1998)

\section{Giant cell arteritis and thyroid dysfunction: multicentre case-control study}

Pierre Duhaut, Hubert Bornet, Laurent Pinède, Sylvie Demolombe-Ragué, Robert Loire, Dominique Seydoux, Jacques Ninet, Jean Pasquier on behalf of the Groupe de Recherche sur l'Artérite à Cellules Géantes

Department of Internal Medicine, E Herriot Hospital, Lyons, Cedex 03 France

Pierre Duhaut, assistant professor Laurent Pinède, assistant professor

Sylvie

Demolombe-Ragué, senior physician Jacques Ninet senior physician Jean Pasquier, senior physician continued over

BMJ 1999:318:434-5

website

extra

An additional table appears on our website

www.bmj.com
The association between giant cell arteritis and thyroid dysfunction remains controversial, but as giant cells are a possible feature of Graves' disease, a common pathway has been suggested. In two series of 101 and 98 patients, the prevalence of hyperthyroidism was reported to be six times higher in cases of giant cell arteritis than in controls. ${ }^{12}$ This was not confirmed on smaller series, ${ }^{3}{ }^{4}$ but 15 cases of hypothyroidism were reported in 31 patients with giant cell arteritis.

We conducted a multicentre case-control study on cases of giant cell arteritis to investigate this relation.

\section{Subjects, methods, and results}

Assuming a prevalence of thyroid dysfunction of $1 \%$ in the general population and an odds ratio of 6 for hyperthyroidism in the patient group, the sample size requested, with $\alpha=0.05$ and $\beta=0.2$, had been estimated to be 269 cases and controls. ${ }^{2}$

We prospectively studied 285 cases of giant cell arteritis (205 women, mean age $74.7 \pm 8.2$ years; 80 men, $72.7 \pm 8.2$ ) newly diagnosed during 1991-96. An experienced pathologist reviewed $262(92 \%)$ of the biopsies: temporal arteritis was confirmed in 145-68 were classed as negative (eight did not have a biopsy), and 72 were classed as having polymyalgia rheumatica alone (22 did not have a biopsy). Blood samples taken up to 48 hours after diagnosis were sent to a reference laboratory.
Controls, randomly selected by computer from residents of Saint-Etienne affiliated to a health insurance company, were matched to cases for age and sex. Of the 222 controls participating, 208 (94\%) agreed to have a blood sample taken (140 women, mean age $74.9 \pm 8.7$ years; 68 men, $71.7 \pm 8.0$ ) (table). Neither cases nor controls had clinical signs or symptoms of thyroid dysfunction.

We measured concentrations of free thyroxine, thyroid stimulating hormone, and antithyroid peroxidase antibodies by standard radioimmunoassays. Antithyroglobulin antibodies were measured as follows: sera were incubated at room temperature with thyroglobulin labelled with 125-iodine, and the immune complexes were precipitated in fetal veal buffer with polyethylene glycol. A positivity threshhold of $50 \mathrm{U} / 1$ for a population free of thyroid disease was determined.

We performed multiple logistic regression. Dependent variables were high and low concentrations of thyroid stimulating hormone, high and low concentrations of free thyroxine, and concentrations of positive or negative antiperoxidase antibodies, positive or negative antithyroglobulin antibodies, and positive or negative antithyroid antibodies (antiperoxidase or antithyroglobulin). Independent variables were case or control, geographical origin (north or south), age, sex, and clinical subgroup of patients.

When we took potential confounders into account, we found no difference between cases and controls. 